\title{
Carcass characteristics of cattle differing in Jersey proportion
}

\author{
D. P. Berry, ${ }^{* 1}$ M. J. Judge, ${ }^{*}$ R. D. Evans, † F. Buckley, ${ }^{*}$ and A. R. Cromie† \\ *Teagasc, Animal and Grassland Research and Innovation Centre, Moorepark, Fermoy P61 P302, Co. Cork, Ireland \\ †Irish Cattle Breeding Federation, Highfield House, Shinagh, Bandon P72 X050, Co. Cork, Ireland
}

\begin{abstract}
Comparison of alternative dairy (cross-)breeding programs requires full appraisals of all revenues and costs, including beef merit. Few studies exist on carcass characteristics of crossbred dairy progeny originating from dairy herds as well as their dams. The objective of the present study was to quantify, using a national database, the carcass characteristics of young animals and cows differing in their fraction of Jersey. The data set consisted of 117,593 young animals and 42,799 cows. The associations between a combination of sire and dam breed proportion (just animal breed proportion when the dependent variable was on cows) with age at slaughter (just for young animals), carcass weight, conformation, fat score, price per kilogram, and total carcass value were estimated using mixed models that accounted for covariances among herdmates of the same sex slaughtered in close proximity in time; we also accounted for age at slaughter in young animals (which was substituted with carcass weight and carcass fat score when the dependent variable was age at slaughter), animal sex, parity of the cow or dam (where relevant), and temporal effects represented by a year-by-month 2 -way interaction. For young animals, the heaviest of the dairy carcasses were from the mating of a HolsteinFriesian dam and a Holstein-Friesian sire $(323.34 \mathrm{~kg})$, whereas the lightest carcasses were from the mating of a purebred Jersey dam to a purebred Jersey sire which were $46.31 \mathrm{~kg}$ lighter (standard error of the difference $=1.21 \mathrm{~kg}$ ). The young animal carcass weight of an $\mathrm{F}_{1}$ Holstein-Friesian $\times$ Jersey cross was 20.4 to $27.0 \mathrm{~kg}$ less than that of a purebred Holstein-Friesian animal. The carcass conformation of a Holstein-Friesian young animal was $26 \%$ superior to that of a purebred Jersey, translating to a difference of 0.78 conformation units on a scale of 1 to 15. Purebred Holstein-Friesians produced carcasses with less fat than their purebred Jersey counterparts. The difference in carcass price per kilogram among the alternative sire-dam breed combinations in-
\end{abstract}

Received April 29, 2018.

Accepted August 14, 2018.

${ }^{1}$ Corresponding author: donagh.berry@teagasc.ie vestigated was minimal, although large differences existed among the different breed types for overall carcass value; the carcass value of a Holstein-Friesian animal was $20 \%$ greater than that of a Jersey animal. Purebred Jersey animals required, on average, $21 \mathrm{~d}$ longer to reach a given carcass weight and fat score relative to a purebred Holstein-Friesian. The difference in age at slaughter between a purebred Holstein-Friesian animal and the mating between a Holstein-Friesian sire with a Jersey dam, and vice versa, was between 7.0 and $8.9 \mathrm{~d}$. A $75.8-\mathrm{kg}$ difference in carcass weight existed between the carcass of a purebred Jersey cow and that of a Holstein-Friesian cow; a 50\% Holstein-Friesian-50\% Jersey cow had a carcass $42.0 \mathrm{~kg}$ lighter than that of a purebred Holstein-Friesian cow. Carcass conformation was superior in purebred Holstein-Friesian compared with purebred Jersey cows. Results from this study represent useful input parameters to populate simulation models of alternative breeding programs on dairy farms, and to help beef farmers evaluate the cost-benefit of rearing, for slaughter, animals differing in Jersey fraction.

Key words: crossbreeding, dairy, beef, conformation, age at slaughter

\section{INTRODUCTION}

Interest is intensifying among dairy producers in the crossing of 2 or more complementary high-genetic-merit breeds in the pursuit of improved overall performance. The benefit of crossing, for example, the Holstein(-Friesian) and Jersey breeds is well documented (for review, see Buckley et al., 2014). Benefits of interbreed crossing include the exploitation of breed complementarity as well as heterosis; the benefits of crossbreeding with Jersey are particularly realized when the price of milk paid to producers is based on milk composition. Using a controlled experiment on 110 Irish dairy cows across multiple years, Prendiville et al. (2009) documented superior milk composition and feed conversion efficiency in first-cross Jersey cows compared with their HolsteinFriesian contemporaries. Based on an analysis of 40 Irish spring-calving commercial dairy farms, Coffey et al. (2016) documented significant heterosis estimates between Holstein-Friesian and Jersey crosses across a 
range of production and reproductive traits. A similar conclusion of superior performance of Holstein-Friesian $\times$ Jersey crossbreds relative to either purebred has also been documented in New Zealand (Lopez-Villalobos et al., 2000a) and elsewhere (Heins et al., 2008). The aforementioned studies, however, all related to traits of the dairy cow and in particular, milk performance, reproductive performance, cow live-weight, and BCS, as well as cow health. Little is known of the beef merit of Jersey crossbred animals, but also the progeny from Jersey (crossbred) dams.

In a controlled study of 120 male cattle, comparing Holstein-Friesian, Norwegian Red crossbreds, and Jersey crossbreds, McNamee at al. (2015) reported a mean difference in carcass weight of $37 \mathrm{~kg}$ between HolsteinFriesians $(314 \mathrm{~kg})$ and Holstein-Friesian $\times$ Jersey firstcross $(277 \mathrm{~kg})$ bulls and steers; the Holstein-Friesian $\times$ Jersey crosses also had a lower dressing percentage than their Holstein-Friesian contemporaries (485 vs. $495 \mathrm{~g} /$ $\mathrm{kg}$ ) as well as a 0.69 -unit (scale 1 to 15 ) poorer carcass conformation score and a 0.81 -unit (scale 1 to 15) lesser carcass fat cover. The study of McNamee at al. (2015), however, was limited to first-cross calves. In their study of 436 purebred young bulls from 15 different breeds slaughtered at 15 mo of age, Alberti et al. (2008) reported a lighter carcass (by $130 \mathrm{~kg}$ ) in purebred Jersey bulls relative to purebred Holstein bulls; no crossbred data were included in their study. Lehmkuhler and Ramos (2008) reported lighter carcass weight (by 76.5 to $125 \mathrm{~kg}$ ) in purebred Jersey steers compared with Holstein-Friesian steers, with a lower dressing percentage also documented for the Jersey steers.

The objective of the present study was to quantify, using a national database, carcass characteristics of heifers, steers, young bulls, and cows differing in Jersey proportion. The results will provide input parameters for the back end of decision support tools to facilitate the derivation of performance from alternative breeding programs on dairy farms. The results will also be useful for beef farmers when evaluating the cost-benefit of rearing, for slaughter, animals differing in Jersey fraction.

\section{MATERIALS AND METHODS}

\section{Data}

Carcass information was available from the Irish Cattle Breeding Federation (Bandon, Co. Cork, Ireland) database on 16,071,706 animals from a range of different breeds and crossbreds slaughtered between the years 2008 and 2018 inclusive. The carcass information available included date of slaughter, carcass weight, carcass conformation score, carcass fat score, carcass price per kilogram, and overall carcass value (i.e., price per $\mathrm{kg} \times$ respective carcass weight), on all bovines slaughtered, regardless of age (i.e., young animals or adults). Carcass weight is measured, on average, $2 \mathrm{~h}$ after slaughter following the removal of the head, legs, thoracic and abdominal organs, and internal fats and hide. In Ireland, carcass conformation and fat scores are graded using video image analysis (Pabiou et al., 2011); carcasses are appraised under the EU beef carcass classification system (EUROP). This 15-point conformation classification system attempts to describe the conformation of the animal mainly based on the round, back, and shoulder; on the 15-point scale (Englishby et al., 2016), a score of 1 reflects poor conformation while that of 15 reflects excellent conformation. Carcass fat score attempts to describe the fat cover on the outside of the carcass and in the thoracic cavity and is graded 1 (low fat score) to 15 (high fat cover). Carcass price per kilogram is a primarily a function of animal sex, age of the animal (i.e., young or mature animal), the prevailing market, and the carcass characteristics (i.e., weight, conformation, and fat score) of the animal. The data set in the present study was stratified into (1) young animals that had never parented an animal, and (2) cows. Information was also available on all inter-herd movements of animals as well as the breed composition of the animal, its sire, and its dam. The heterosis coefficient of each animal was calculated based on the breed composition of the sire and dam, and all breed-combination heterosis coefficients were summed to generate a general heterosis coefficient per animal. Information was also available on the date of birth of the animal, the date of each calving per animal (where relevant), and the respective parity number. All subsequent analyses were undertaken separate for young animals (based on the breed composition of their parents) and for adult cows (based on their own breed composition).

\section{Young Animals}

The young animal category considered in the present study included singleton heifers, steers, and bulls. Based on the frequency distribution of age at slaughter for each sex, the data used were restricted to heifers and steers slaughtered between 14 and 36 mo of age and young bulls slaughtered between 14 and 24 mo of age. Age at slaughter was categorized into months for subsequent use in the analysis. Only young animals from dams with $\geq 75 \%$ of their breed composition made up of Holstein-Friesian and Jersey combined were retained. No restriction was imposed on the breed of the sire of the young animals. The parity of each dam when the animal was born was also available and was categorized as 1, 2, 3, 4, and 5+. Furthermore, animals 
could not have resided in more than 2 herds during their lifetime, and animals had to have been present in the herd they were slaughtered from for at least $100 \mathrm{~d}$ before slaughter.

Each young animal was allocated to a contemporary group for subsequent use in the statistical model to account for the covariances that are likely to exist among animals of the same sex slaughtered in proximity in time from the same farm. Contemporary group was therefore defined as herd-year-season-sex of slaughter generated using an algorithm routinely used in Irish national genetic evaluations (Berry and Evans, 2014; McHugh et al., 2014; Berry et al., 2017). Within a herd, the algorithm clusters animals of the same sex that are slaughtered in close proximity $(\leq 10 \mathrm{~d})$ of each other; when $<10$ animals are initially clustered, the group is amalgamated with an adjacent contemporary group to form a single larger group. This process is repeated until the contemporary group contains $\geq 10$ animals, provided the number of days between the initial and final slaughter date does not exceed 90. Only animals within contemporary groups of at least 4 animals were retained. Furthermore, only contemporary groups containing at least one animal with some proportion of Jersey were retained.

The final data set consisted of 117,593 young animals (14,792 heifers, 64,903 steers, and 37,898 bulls) from 8,613 contemporary groups originating from 3,878 herds and slaughtered in 33 Irish abattoirs. The animals were from 107,378 dams and 12,594 sires; the animal originated from a range of breeds of sires including purebred Angus (18,487 animals), Jersey (5,283 animals), Holstein-Friesian (76,977 animals), Belgian Blue (1,751 animals), Charolais (561 animals), Hereford (7,933 animals), Limousin (2,700 animals), Simmental (755 animals), and Saler (151 animals), with the remainder from crossbred bulls (e.g., Jersey $\times$ Holstein-Friesian crosses) or minority breeds.

\section{Cows}

Only cows with $\geq 75 \%$ of their breed makeup comprising Holstein-Friesian and Jersey combined were retained; all cows were of parity $\leq 10$ and only cows slaughtered within $450 \mathrm{~d}$ of calving were considered further. Days postcalving was categorized into 12 categories as $<30 \mathrm{~d}, 30$ to $59 \mathrm{~d}, 60$ to $89 \mathrm{~d}, \ldots, 270$ to $299 \mathrm{~d}, 300$ to $399 \mathrm{~d}$, and 400 to $450 \mathrm{~d}$. Cow parity was categorized as 1, 2, 3, 4, and 5+. Contemporary group was defined as herd-year-season of slaughter generated using the aforementioned algorithm. Only cows within contemporary groups of at least 4 cows containing at least one cow with some proportion of Jersey were retained. The final data set consisted of 42,799 cows from 4,528 contemporary groups originating from 1,791 herds and slaughtered in 28 Irish abattoirs.

\section{Analysis}

All analyses were undertaken using linear mixed models with contemporary group included as a random effect. A 2-way interaction between year and month of slaughter was included as a fixed effect in all models to account for temporal trends. How breed was considered in the statistical model depended on whether the analysis was on young animals or cows. When the dependent variable was a carcass trait of a young animal, the breed proportion of both the sire and the dam, represented separately as a linear covariate on each of the 10 main breeds (Jersey, Holstein-Friesian, Angus, Belgian Blue, Charolais, Hereford, Limousin, Simmental, Saler, Shorthorn) was included in all models; however, when the dependent variable was a carcass trait of a cow, then the breed composition of just the cow herself (i.e., not the breed of dam or the sire) for each of the 10 aforementioned breeds was included as separate covariates. A covariate representing the general heterosis coefficient of the animal was included in all models. No nonlinear association between the Holstein-Friesian and Jersey breed proportions with any carcass characteristic was detected. A 2-way interaction between animal sex (i.e., heifer, steer, or young bull) and age at slaughter in months was included as a fixed effect for the analysis of carcass traits in young animals, as was the fixed effect of dam parity. When a carcass characteristic in cows was the dependent variable, then a 2-way interaction between parity of cow and the categorized variable representing days since calving was included as a fixed effect. No multi-collinearity existed in the developed models.

Least squares means for each carcass characteristic in young animals for a range of different sire-dam breed combinations were extracted based on a referent animal and linear functions of the model solutions. The referent young animal was a steer slaughtered at 28 mo of age; the exception was when the dependent variable was age at slaughter, for which the referent animal was a steer slaughtered at a carcass weight of $320 \mathrm{~kg}$ and a carcass fat score of 7 . Least squares means of interest in the young animals focused on the progeny of dams that were $0 \%$ Jersey, $33 \%$ Jersey (i.e., expectation from a 2-way rotational cross where the sire of the cow was not Jersey), 50\% Jersey (i.e., $\mathrm{F}_{1}$ crossbred), $66 \%$ Jersey (i.e., expectation from a 2 -way rotational cross where the sire of the cow was Jersey), and 100\% Jersey; in all instances the remaining breed proportion of the dam 
Table 1. Number of animals (N) and raw means (SD in parentheses) for carcass weight, carcass conformation, carcass fat score, price, value, and age at slaughter for heifers, steers, young bulls, and cows

\begin{tabular}{lccccccc}
\hline Animal & $\mathrm{N}$ & Weight $(\mathrm{kg})$ & Conformation $^{1}$ & Carcass fat $^{1}$ & Price $(€ / \mathrm{kg})^{*}$ Value $(€)$ & Age $(\mathrm{d})$ \\
\hline Heifers & 14,792 & $266.55(36.84)$ & $5.25(1.50)$ & $7.39(1.74)$ & $3.81(0.56)$ & $1022.9(221.47)$ & $725.25(112.94)$ \\
Steers & 64,903 & $318.77(41.91)$ & $6.36(1.40)$ & $6.36(1.40)$ & $3.63(0.43)$ & $1160.92(215.27)$ & $812.62(115.74)$ \\
Bulls & 37,898 & $303.71(47.25)$ & $5.11(1.41)$ & $4.95(0.86)$ & $3.65(0.37)$ & $1112.11(217.96)$ & $628.31(81.78)$ \\
Cows & 42,799 & $266.91(53.68)$ & $2.46(1.14)$ & $6.04(2.49)$ & $2.76(0.70)$ & $763.42(294.90)$ & $2192.92(851.92)$ \\
\hline
\end{tabular}

${ }^{1}$ Carcass conformation was on a scale from 1 (poor) to 15 (excellent); carcass fat was on a scale from 1 (low) to 5 (high).

(i.e., 1 - the Jersey proportion) was assumed to be Holstein-Friesian. The sire of the calf of interest was assumed to be either a purebred Jersey bull, a $50 \%$ Jersey-50\% Holstein-Friesian bull, a purebred HolsteinFriesian bull, or a purebred Angus bull; Angus was chosen to represent the predominant beef breed used in Irish dairy herds. Only a general heterosis effect was estimated (and thus considered in the derivation of the least squares means) for all crosses, irrespective of the sire-dam breed combination.

When the dependent variable in the model was a carcass characteristics of a cow, then the least squares means for each carcass characteristic for a range of different cow Jersey fractions were extracted based on a referent cow and linear functions of the model solutions. The referent cow was a third-parity cow slaughtered between 270 and $300 \mathrm{~d}$ after calving. The least squares means of interest for carcass characteristics of cows differing in Jersey fraction was $0,25,33,50,66,75$, or $100 \%$ Jersey. In all cases, the appropriate (general) heterosis coefficient was used in the calculation of the least squares means.

\section{RESULTS}

Summary statistics for the young animals and cows are given in Table 1. Steers were, on average, the heaviest but were also, on average, the oldest at slaughter. Figure 1 summarizes the frequency distribution of the proportion Jersey in the dams of the young animals; $71.3 \%$ of the dams had no Jersey fraction. The regression coefficients (SE in parentheses) on the general heterosis term in the model for young animals were 1.21 (0.49), 0.48 (0.01), 0.21 (0.01), 0.04 (0.002), 12.69 (1.76), and -4.56 (1.12) for carcass weight, conformation, fat score, price, value, and age at slaughter, respectively. The regression coefficients (SE in parentheses) on the general heterosis term in the model for cows were -4.05 (0.67), 0.22 (0.02), 0.41 (0.03), 0.03 (0.007), and -9.77 (3.22) for carcass weight, conformation, fat score, price, and value, respectively. Least squares means for carcass weight, conformation, and fat score in steer progeny originating from the mating of a sire and dam differ- ing in Jersey proportion are given in Table 2, whereas Table 3 summarizes the least squares means from such crosses for carcass price per kilogram, carcass value, and age at slaughter. Least squares means for heifers and bulls are in Supplemental Tables S1 to S4 (https: //doi.org/10.3168/jds.2018-14992). The heaviest dairy carcasses were from a Holstein-Friesian dam mated to a Holstein-Friesian sire $(323.24 \mathrm{~kg})$ and the lightest carcasses were from the mating of a purebred Jersey dam to a purebred Jersey sire, which was $46.31 \mathrm{~kg}$ lighter [standard error of the difference $($ SED $)=1.21 \mathrm{~kg}$ ]; the carcass weight of an $\mathrm{F}_{1}$ Holstein-Friesian $\times$ Jersey cross was 20.4 to $27.0 \mathrm{~kg}$ lighter $(P<0.001)$ than that of a purebred Holstein-Friesian steer. The carcass conformation of a Holstein-Friesian steer was $26 \%$ superior to that of a purebred Jersey steer, translating to a difference of 0.78 conformation units on a scale of 1 to 15 . The carcass fat score of a purebred Holstein-Friesian steer was lower (i.e., less fat; $P<0.001$ ) than that of a purebred Jersey animal (Table 2).

The difference in carcass price per kilogram among the alternative Holstein-Friesian and Jersey sire-dam breed combinations investigated was minimal (Table $3)$; the greatest difference $(P<0.001)$ was when a Holstein-Friesian purebred steer $(€ 3.38 / \mathrm{kg})$ was compared with a purebred Jersey steer $(€ 3.30 / \mathrm{kg}$ ). Price per kilogram of the steer progeny from a Jersey sire mated to a Holstein-Friesian cow or vice versa was not different from that of a purebred Holstein-Friesian (Table 3). Large differences existed among the different breed types for overall carcass value; the carcass value of a Holstein-Friesian steer was $20 \%$ greater than that of a Jersey steer, equating to a monetary difference of $€ 184.13$. The difference in carcass value for an $F_{1}$ Holstein-Friesian $\times$ Jersey cross relative to a purebred Holstein-Friesian was between €68.68 and €98.14. Purebred Jersey steers required, on average, $21.1 \mathrm{~d}$ more to reach a given carcass weight and fat score (here, assumed to be $320 \mathrm{~kg}$ and 7 units, respectively) relative to a purebred Holstein-Friesian. The difference in age at slaughter between a purebred Holstein-Friesian steer and a Holstein-Friesian $\times$ Jersey cross was between 7.0 and $8.9 \mathrm{~d}$. 


\section{Carcass Characteristics of Progeny from Angus Sires}

The carcass characteristics of steer progeny from dams differing in Jersey proportion when mated to a purebred Angus sire are given in Tables 2 and 3. The difference in carcass weight and conformation score between steer progeny from a purebred Holstein-Friesian dam and steer progeny from a purebred Jersey dam was $26.49 \mathrm{~kg}(\mathrm{SED}=1.18 \mathrm{~kg})$ and 0.37 units $(\mathrm{SED}=$ 0.039), respectively, with the Jersey dam being inferior for both metrics; the carcass weight and conformation from an $\mathrm{F}_{1}$ Holstein-Friesian $\times$ Jersey dam was 13.25 $\mathrm{kg}$ and 0.18 units less $(P<0.01)$ than that from a Holstein-Friesian dam. The steer progeny from purebred Jersey dams were slaughtered $11.5 \mathrm{~d}$ later $(P<0.001)$ than the steer progeny from Holstein-Friesian dams. Relative to the steer progeny from a purebred HolsteinFriesian dam, the percentage reduction in carcass value when the dam was $33,50,66$, and $100 \%$ Jersey was 3 , 5,6 , and $9 \%$, respectively.

\section{Carcass Characteristics of Cows}

Least squares means for different carcass metrics of cows varying in Jersey proportion are given in Table 4. A 75.8-kg difference in carcass weight existed, on average, between the carcass of a purebred Jersey cow and that of a Holstein-Friesian cow; a 50\% HolsteinFriesian-50\% Jersey cow had, on average, a carcass $42.0 \mathrm{~kg}$ lighter than a purebred Holstein-Friesian cow. A difference in price of $€ 0.39 / \mathrm{kg}$ of carcass was evident when comparing a purebred Jersey with a purebred Holstein-Friesian which, when coupled with the difference in carcass weight, resulted in a difference in value of $€ 285.90$. The carcass conformation of purebred Holstein-Friesian cows was 0.52 units (scale 1 to 15 ) superior to that of purebred Jersey cows and the fat score of purebred Holstein-Friesian cows was 0.22 units (scale 1 to 15) lower (i.e., less fat) than that of purebred Jersey cows.

\section{DISCUSSION}

The contribution of beef output to the revenue of dairy enterprises is well recognized, with van der Werf et al. (1998) suggesting that surplus calves and cull cow sales constitute 10 to $20 \%$ of the gross income in a dairy herd. Therefore, ramifications on revenue from beef must be considered when evaluating alternative breeding programs on dairy farms. Although some studies have attempted to quantify the difference in beef merit of Holstein-Friesian versus Holstein-Friesian $\times$ Jersey crosses or purebred Jerseys (Barton et al., 1994; Lehm-

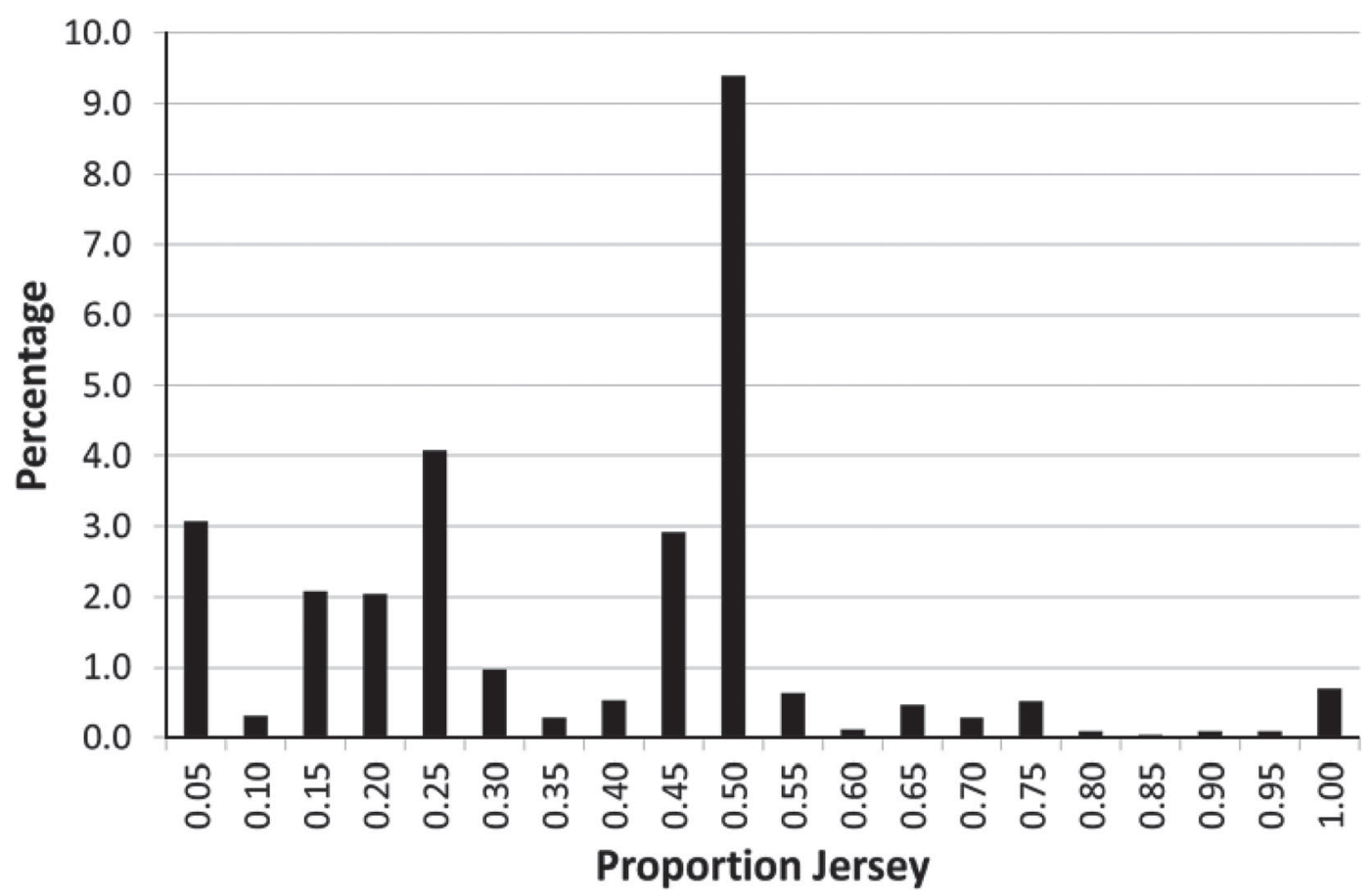

Figure 1. Frequency distribution of dams differing in Jersey proportion; not included are dams with $0 \%$ Jersey, which represented $71.3 \%$ of the data. 
CARCASS CHARACTERISTICS OF JERSEY CROSSBREDS
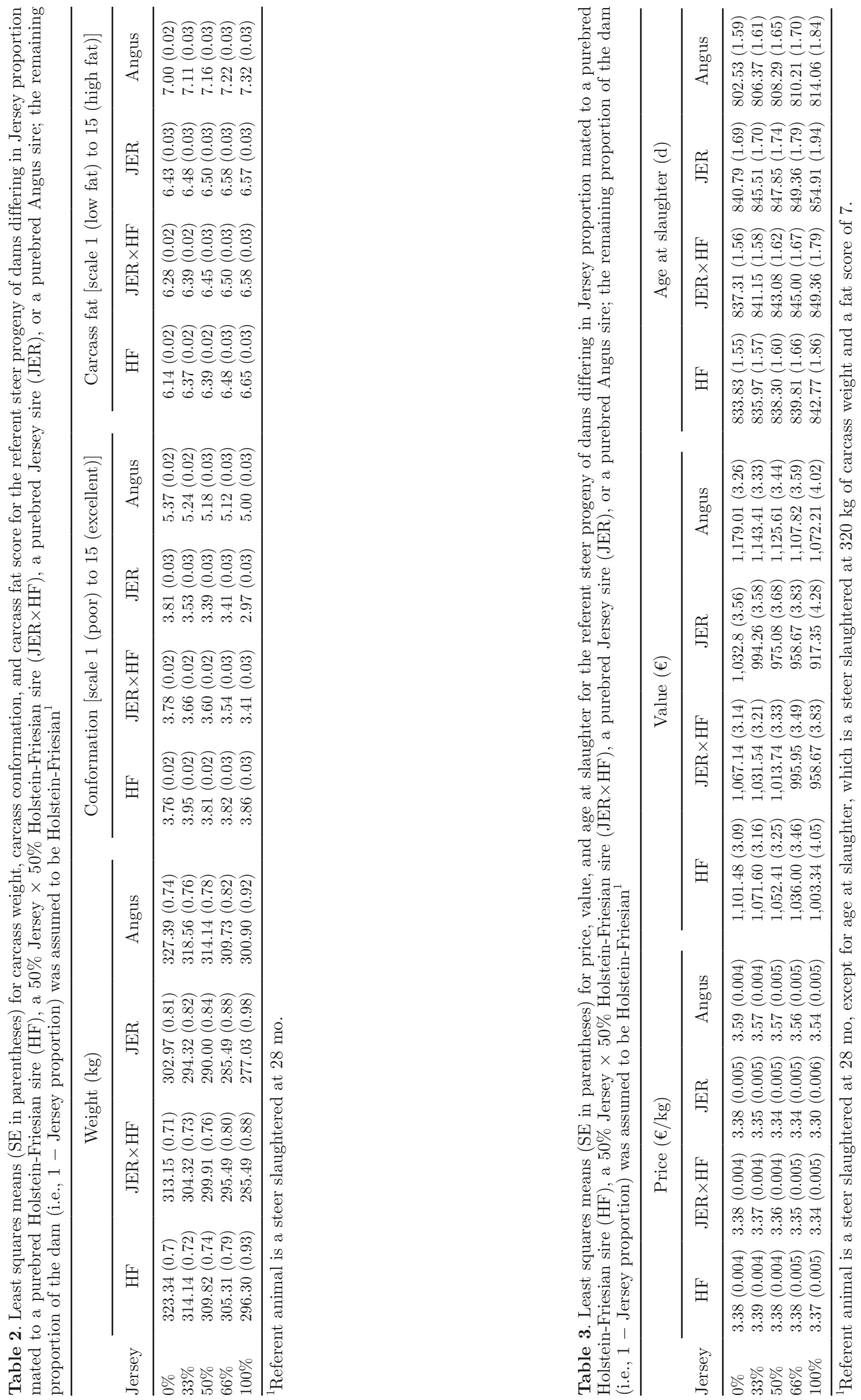
kuhler and Ramos, 2008; McNamee et al., 2015), these studies have generally been limited in size (Barton et al., 1994; Lehmkuhler and Ramos, 2008; McNamee et al., 2015), were confined to only the first cross between a Holstein-Friesian and a Jersey (McNamee et al., 2015), and in some cases may now be outdated (Purchas and Barton, 1976; Barton et al., 1994), given the intervening rate of genetic gain in some breeds. Moreover, the literature of carcass characteristics of Jersey crossbreed cows is sparse. Knowing not only the carcass merit of the first-cross progeny but also of the progeny of subsequent (e.g., rotational) crosses is crucial for appropriate long-term modeling of crossbreeding strategies, which have generally heretofore only considered performance measures realized in mature dairy cows (Lopez-Villalobos et al., 2000b).

Results from the present study demonstrate the inferior carcass characteristics associated with increasing Jersey proportion in either young animals or the cows themselves. Nonetheless, especially when mated to a beef bull (here, an Angus), there was a difference of only $€ 53.40$ between the steer progeny of a Holstein-Friesian dam and that of a crossbred $50 \%$ Holstein-Friesian $\times$ $50 \%$ Jersey dam; the latter, however, required $5.76 \mathrm{~d}$ to reach a fixed carcass weight and fat score, thus incurring a greater cost. Although no feed intake data were available in the present study, McNamee et al. (2015), while failing to identify any significant difference in feed intake per day for their 3 genotypes investigated, did document a greater intake per kilogram of mean live-weight in first-cross Holstein-Friesian $\times$ Jersey crossbred bulls relative to purebred Holstein-Friesian bulls; no such difference was detected in steers. Further research may be merited to elucidate differences in daily feed intake among animals differing in Jersey proportion, thus facilitating a more accurate quantification of the total cost of producing carcasses differing in Jersey proportion. Using the carcass values reported in the present study, this additional information would be invaluable in calculating breakeven costs for the production of animals differing in Jersey proportion. An additional advantage of meat from animals with a Jersey bloodline may be the documented superior meat quality and nutritive value of Jersey meat compared with that of many other breeds (Purchas and Barton, 1976; Siebert et al., 2003). There is a strong willingness among consumers to pay for more tender meat (Boleman et al., 1997).

Although the carcass characteristics of Jersey crossbred or purebred animals were generally inferior to that of their Holstein-Friesian contemporaries, this does not imply that remedial action is required. The national breeding objective in Ireland, the Economic Breeding Index (EBI; Berry et al., 2007), already includes emphasis on progeny beef merit (Roche et al., 2017) to reflect the contribution to the dairy producer from the sale of surplus young animals. A carcass value for cull cows, as well as the maintenance cost of cows differing in live-weight, is also considered within the EBI. Genetic evaluations in Ireland are undertaken across breeds, and animals from all breeds are ranked on the EBI, implying that the same emphasis is placed on beef merit across all breeds. Although genetic merit for profit accruing from male calves is lesser for Jersey-bred animals, these Jersey-bred animals excel in genetic merit for maintenance requirements due to their lighter mature cow weight (Prendiville et al., 2009). This lighter cow is one of the main attractions of the Jersey breed as dairy producers strive to improve efficiencies of production. Given the strong genetic correlation (0.75; McHugh et al., 2011) between live-weight in young animals close to slaughter and cows, increasing the live-weight of young animals destined for slaughter while retaining cow mature size would prove slow. Based on the genetic parameters presented by McHugh et al. (2011) for Irish cattle of a genetic standard deviation for young animals close

Table 4. Least squares means (SE in parentheses) for carcass weight, carcass conformation, carcass fat score, price, and value for cows differing in Jersey proportion; the remaining proportion of the cow (i.e., 1 - Jersey proportion) was assumed to be Holstein-Friesian ${ }^{1}$

\begin{tabular}{lccccc}
\hline Jersey & Weight $(\mathrm{kg})$ & Conformation $^{2}$ & Carcass fat $^{2}$ & Price $(€ / \mathrm{kg})$ & Value $(€)$ \\
\hline $0 \%$ & $280.08(1.62)$ & $2.44(0.04)$ & $5.94(0.08)$ & $2.61(0.018)$ & $758.04(8.09)$ \\
$25 \%$ & $259.11(1.60)$ & $2.42(0.04)$ & $6.20(0.08)$ & $2.52(0.018)$ & $681.68(8.00)$ \\
$33 \%$ & $252.29(1.60)$ & $2.43(0.04)$ & $6.30(0.08)$ & $2.50(0.018)$ & $657.35(8.03)$ \\
$50 \%$ & $238.13(1.65)$ & $2.39(0.04)$ & $6.45(0.08)$ & $2.44(0.019)$ & $605.32(8.24)$ \\
$66 \%$ & $227.29(1.66)$ & $2.26(0.04)$ & $6.37(0.09)$ & $2.37(0.019)$ & $563.00(8.29)$ \\
$75 \%$ & $221.22(1.69)$ & $2.16(0.04)$ & $6.31(0.09)$ & $2.33(0.019)$ & $538.73(8.45)$ \\
$100 \%$ & $204.30(1.86)$ & $1.92(0.05)$ & $6.16(0.10)$ & $2.22(0.021)$ & $472.14(9.25)$ \\
\hline
\end{tabular}

${ }^{1}$ Referent cow is a third-parity cow slaughtered between 270 and $300 \mathrm{~d}$ after calving.

${ }^{2}$ Carcass conformation was on a scale from 1 (poor) to 15 (excellent); carcass fat was on a scale from 1 (low) to 15 (high). 
to slaughter and cows of 22.5 and $26.1 \mathrm{~kg}$, respectively, and a genetic correlation of 0.75 between both traits, then the genetic standard deviation in young animal live-weight genetically independent of cow live-weight will be $14.88 \mathrm{~kg}$. Assuming a dressing percentage of $485 \mathrm{~g} / \mathrm{kg}$ in first-cross Holstein-Friesian $\times$ Jersey bulls and steers (McNamee et al., 2015), this equates to a genetic standard deviation in carcass weight (assuming no genetic difference in dressing percentage) of 7.22 $\mathrm{kg}$. Hence, limited scope exists to change young animal carcass weight in Jerseys without affecting mature cow size and hence the favorable (gross) efficiency characteristics of the Jersey breed. The scope is even less if attempting to alter cull cow carcass weight without affecting the maintenance requirement of the cow. Assuming maintenance is directly related to live-weight, then the scope for improvement is simply the genetic variability in cull cow dressing percentage; the scientific literature lacks estimates of genetic variability in dressing percentage of mature cows, although Riley et al. (2002) reported a genetic standard deviation of $1.605 \%$ for dressing percentage in Braham cattle slaughtered at $443.61 \mathrm{~kg}$. Nonetheless, given the superior reproductive performance of, particularly, crossbred dairy cows, the actual cow culling rate is expected to be lower.

X-Chromosome-carrying sexed semen provides an opportunity to optimize crossbreeding strategies to the benefit of both the dairy producer and also the downstream beef sector. In such situations, sufficient cows are mated to X-carrying sperm from a dairy breed sire to generate sufficient replacement females; the remaining cows can then be mated to bulls of beef breeds, partly ameliorating the unfavorable carcass characteristics of Jersey fraction. For illustrative purposes only, an Angus bull was used in the present study; this Angus effect, of course, simply reflects the breed average. It is possible, therefore, to use genetically superior (beef) bulls based on a terminal index (Connolly et al., 2016), which would improve the carcass characteristics of the resulting progeny (Clarke et al., 2009; Connolly et al., 2016) but could also achieve this without necessarily increasing calving dystocia (McHugh et al., 2014). Despite detecting a significant interaction between animal genetic merit and subsequent performance depending on whether or not the cattle originated from a dairy herd (bucket reared) or a beef herd (suckled until weaning), Connolly et al. (2016) concluded that the biological significance of the interaction was minimal and that a beef terminal index functions equally well irrespective of the origin of the cattle. Hence, strategies do exist to lessen the effect of Jersey bloodline on beef merit while still protecting one of the main benefits of Jersey cows, which is their superior gross efficiency.

\section{ACKNOWLEDGMENTS}

This publication arose from research supported in part by a research grant from Science Foundation Ireland (Dublin) and the Department of Agriculture, Food and Marine on behalf of the Government of Ireland under the Grant 16/RC/3835 (VistaMilk; Dublin, Ireland) as well as funding from the Research Stimulus Fund (BreedQuality and GREENBREED; Dublin, Ireland) and Meat Technology Ireland (MTI; Dublin, Ireland), a co-funded industry/Enterprise Ireland project (TC 2016 002).

\section{REFERENCES}

Alberti, P., B. Panea, C. Sanudo, J. L. Olleta, G. Ripoll, P. Ertberg, M. Christensen, S. Gigli, S. Failla, S. Concetti, J.-F. Hocquette, R. Jailler, S. Rudel, G. Renand, G. R. Nute, R. I. Richardson, and J. L. Williams. 2008. Live weight, body size and carcass characteristics of young bulls of fifteen European breeds. Livest. Sci. 114:19-30.

Barton, R. A., J. L. Donaldson, F. R. Barnes, C. F. Jones, and H. J. Clifford. 1994. Comparison of Friesian, Friesian-Jersey and Jersey steers in beef production. N. Z. J. Agric. Res. 37:51-58.

Berry, D. P., A. R. Cromie, and M. M. Judge. 2017. Large exploitable genetic variability exists to shorten age at slaughter in cattle. J. Anim. Sci. 95:4526-4532.

Berry, D. P., and R. D. Evans. 2014. Genetics of reproductive performance in seasonal calving beef cows and its association with performance traits. J. Anim. Sci. 92:1412-1422.

Berry, D. P., L. Shalloo, A. R. Cromie, R. F. Veerkamp, P. Dillon, P. R. Amer, J. F. Kearney, R. D. Evans, and B. Wickham. 2007. The Economic Breeding Index: A generation on. Technical report to the Irish Cattle Breeding Federation. Bandon, Co. Cork, Ireland.

Boleman, S. J., S. L. Boleman, R. K. Miller, J. F. Taylor, H. R. Cross, T. L. Wheeler, M. Koohmaraie, S. D. Shackelford, M. F. Miller, R. L. West, D. D. Johnson, and J. W. Savell. 1997. Consumer evaluation of beef of known categories of tenderness. J. Anim. Sci. 75:1521-1524.

Buckley, F., N. Lopez-Villalobos, and B. J. Heins. 2014. Crossbreeding: Implications for dairy cow fertility and survival. Animal 8:122-133.

Clarke, A. M., M. J. Drennan, M. McGee, D. A. Kenny, R. D. Evans, and D. P. Berry. 2009. Intake, growth and carcass traits in male progeny of sires differing in genetic merit for beef production. Animal 3:791-801.

Coffey, E. L., B. Horan, R. D. Evans, and D. P. Berry. 2016. Milk production and fertility performance of Holstein, Friesian, and Jersey purebred cows and their respective crosses in seasonal-calving commercial farms. J. Dairy Sci. 99:5681-5689.

Connolly, S. M., A. R. Cromie, and D. P. Berry. 2016. Genetic differences based on a beef terminal index are reflected in future phenotypic performance differences in commercial beef cattle. Animal 10:736-745.

Englishby, T. M., G. Banos, K. L. Moore, M. P. Coffey, R. D. Evans, and D. P. Berry. 2016. Genetic analysis of carcass traits in beef cattle using random regression models. J. Anim. Sci. 94:1354-1364.

Heins, B. J., L. B. Hansen, A. J. Seykora, D. G. Johnson, J. G. Linn, J. E. Romano, and A. R. Hazel. 2008. Crossbreds of Jersey $\times$ Holstein compared with pure Holsteins for production, fertility, and body and udder measurements during first lactation. J. Dairy Sci. 91:1270-1278.

Lehmkuhler, J. W., and M. H. Ramos. 2008. Comparison of dairy beef genetics and dietary roughage levels. J. Dairy Sci. 91:2523-2531.

Lopez-Villalobos, N., D. J. Garrick, H. T. Blair, and C. W. Holmes. 2000b. Possible effects of 25 years of selection and crossbreeding 
on the genetic merit and productivity of New Zealand dairy cattle. J. Dairy Sci. 83:154-163.

Lopez-Villalobos, N., D. J. Garrick, C. W. Holmes, H. T. Blair, and R. J. Spelman. 2000a. Effects of selection and crossbreeding strategies on industry profit in the New Zealand dairy industry. J. Dairy Sci. 83:164-172.

McHugh, N., A. R. Cromie, R. D. Evans, and D. P. Berry. 2014. Validation of national genetic evaluations for maternal beef cattle traits using Irish field data. J. Anim. Sci. 92:1423-1432.

McHugh, N., R. D. Evans, P. R. Amer, A. G. Fahey, and D. P. Berry. 2011. Genetic parameters for cattle price and body weight from routinely collected data at livestock auctions and commercial farms. J. Anim. Sci. 89:29-39.

McNamee, A., M. G. Keane, D. A. Kenny, A. P. Moloney, F. Buckley, and E. G. O' Riordan. 2015. Beef production from Holstein-Friesian, Norwegian Red $\times$ Holstein-Friesian and Jersey $\times$ Holstein-Friesian male cattle reared as bulls or steers. Livest. Sci. 173:95-105.

Pabiou, T., W. F. Fikse, P. R. Amer, A. R. Cromie, A. Nasholm, and D. P. Berry. 2011. Genetic variation in wholesale carcass cuts predicted from digital images in cattle. Animal 5:1720-1727.

Prendiville, R., K. M. Pierce, and F. Buckley. 2009. An evaluation of production efficiencies among lactating Holstein-Friesian, Jer- sey, and Jersey x Holstein-Friesian cows at pasture. J. Dairy Sci 92:6176-6185.

Purchas, R. W., and R. A. Barton. 1976. The tenderness of meat of several breeds of cattle raised under New Zealand pastoral conditions. N. Z. J. Agric. Res. 19:421-428.

Riley, D. G., C. C. Jr Chase, A. C. Hammond, R. L. West, D. D Johnson, T. A. Olson, and S. W. Coleman. 2002. Estimated genetic parameters for carcass traits of Brahman cattle. J. Anim. Sci. 80:955-962.

Roche, J. R., D. P. Berry, A. M. Bryant, C. R. Burke, S. T. Butler, P. G. Dillon, D. J. Donaghy, B. Horan, K. A. Macdonald, and K. L. Macmillan. 2017. A 100-Year Review: A century of change in temperate grazing dairy systems. J. Dairy Sci. 100:10189-10233.

Siebert, B. D., W. S. Pitchford, Z. A. Kruk, H. Kuchel, M. P. Deland, and C. D. Bottema. 2003. Differences in delta9 desaturase activity between Jersey- and Limousin-sired cattle. Lipids 38:539-543.

van der Werf, J. H. J., L. H. van der Waaij, A. F. Groen, and G. de Jong. 1998. An index for beef and veal characteristics in dairy cattle based on carcass traits. Livest. Prod. Sci. 54:11-20. 